\title{
Connective tissue disorder due to lysyl hydroxylase-3 deficiency
}

INSERM

\section{Source}

INSERM. (1999). Orphanet: an online rare disease and orphan drug data base. Connective tissue disorder due to lysyl hydroxylase-3 deficiency. ORPHA:300284

Connective tissue disorder due to lysyl hydroxylase-3 deficiency is a rare, genetic disease, caused by lack of lysyl hydrohylase 3 (LH3) activity, characterized by multiple tissue and organ involvement, including skeletal abnormalities (club foot, progressive scoliosis, osteopenia, pathologic fractures), ocular involvement (flat retinae, myopia, cataracts) and hair, nail and skin anomalies (coarse, abnormally distributed hair, skin blistering, reduced palmar creases, hypoplastic nails). Patients also present intrauterine growth retardation, facial dysmorphism (flat facial profile, low-set ears, shallow orbits, short and upturned nose, downturned corners of mouth) and joint flexion contractures. Growth and developmental delay, bilateral sensorineural deafness, friable diaphragm and later-onset spontaneous vascular ruptures are additional reported features. 